\title{
Numerical study of the effect of geosynthetic encasement on the behaviour of granular columns
}

\author{
M. Khabbazian ${ }^{1}$, V. N. Kaliakin ${ }^{2}$ and C. L. Meehan ${ }^{3}$ \\ ${ }^{1}$ Graduate Student, Department of Civil and Environmental Engineering, 301 DuPont Hall, University \\ of Delaware, Newark, DE 19716, USA, Telephone: +1 302831 8053, Telefax: +1 3028313640 , \\ E-mail: majid@udel.edu \\ ${ }^{2}$ Associate Professor, Department of Civil and Environmental Engineering, 301 DuPont Hall, University \\ of Delaware, Newark, DE 19716, USA, Telephone: +1 302831 2409, Telefax: +1 3028313640 , \\ E-mail: kaliakin@udel.edu \\ ${ }^{3}$ Assistant Professor, Department of Civil and Environmental Engineering, 301 DuPont Hall, University \\ of Delaware, Newark, DE 19716, USA, Telephone: +1 302831 6074, Telefax: +1 3028313640 , \\ E-mail: cmeehan@udel.edu
}

Received 15 September 2009, revised 1 February 2010, accepted 2 February 2010

\begin{abstract}
In very soft soils, the use of granular columns can be restricted due to the lack of adequate lateral confining pressure. In these conditions, the columns can be encased by a suitable geosynthetic to provide the required confining pressure and to increase their bearing capacity. Using a high-strength geosynthetic for confinement not only increases the strength of a granular column, but also prevents lateral displacement of the column into the very soft surrounding soil. This paper describes three-dimensional finite element analyses carried out to simulate the behaviour of a single granular column with and without encasement in a very soft clay using the computer program ABAQUS. Comprehensive numerical analyses were performed to study the influence of the geosynthetic stiffness, the friction and dilation angle of the column material, the length of geosynthetic encasement, the diameter of the column, the length of the column and the coefficient of in situ lateral earth pressure. Model results show that the stress-settlement behaviour of granular columns can be significantly improved by encasing them. The stiffness of the encasement was found to have a major effect on the stress-settlement response of encased columns and their associated load-carrying capacity. For partially encased columns, the optimum length of encasement was found to be a function of the stress that is applied to the column.
\end{abstract}

KEYWORDS: Geosynthetics, Granular column, Stone column, Granular pile, Geosynthetic encasement, Soft soil, Finite element analysis

REFERENCE: Khabbazian, M., Kaliakin V. N. \& Meehan, C. L. (2010). Numerical study of the effect of geosynthetic encasement on the behaviour of granular columns. Geosynthetics International 17, No. 3, 132-143. [doi: 10.1680/gein.2010.17.3.132]

\section{INTRODUCTION}

Granular columns, which are sometimes referred to as stone columns, sand columns, or granular piles, are columns of compacted sand or gravel that are inserted into a soft foundation using a variety of installation techniques (e.g. Aboshi et al. 1979; Barksdale and Bachus 1983; Bergado et al. 1996; Elias et al. 2006; Araujo et al. 2009). This technology is commonly used for ground improvement, especially for problematic soils that underlie structures that can tolerate some settlement such as road embankments and storage tanks (e.g. Greenwood 1970; Ambily and Gandhi 2007). Granular columns are also utilised for supporting lightly loaded foundations such as those that are encountered in low-rise buildings (e.g. Greenwood 1970; Barksdale and Bachus 1983). The increasing use of granular columns is attributed to their proven successes in increasing bearing capacity, reducing total and differential settlements, increasing the time rate of settlement and reducing the liquefaction potential of sands (Barksdale and Bachus 1983; Juran and Riccobono 1991; Priebe 1995; Muir-Wood et al. 2000).

Granular columns under compressive loads experience failure modes such as bulging (Hughes and Withers 1974; Hughes et al. 1975), general shear failure (Madhav and Vitkar 1978), sliding (Aboshi et al. 1979) and punching into soft soils located beneath the columns (Brauns 1978). However, in soft clays, the most common failure mode for granular columns is bulging (Madhav and Miura 1994).

It is well established that granular columns can be effective in soft soils with undrained shear strengths 
ranging from 15 to $50 \mathrm{kPa}$ (Barksdale and Bachus 1983; Juran et al. 1988). In very soft soils (e.g. with undrained strengths $<15 \mathrm{kPa}$ ), due to the lack of required lateral confining pressure, the use of granular columns can be problematic or even impossible (Juran and Riccobono 1991; Paul and Ponomarjow 2004). Some researchers report that granular columns can be successfully installed and used in soils with undrained shear strengths as low as 5-10 kPa (e.g. Greenwood 1970; Raju 1997). However, although column installation in soils this soft is feasible, larger settlements under load are typically observed, making application of this technology a bit more challenging in these soils (Greenwood 1970).

To increase the applicability of granular columns for use in very soft soils (e.g. those with undrained strengths $<15 \mathrm{kPa}$ ), or to improve column stress-settlement response in all soil types, different techniques have been proposed to enhance the performance of granular columns: Aboshi et al. (1979) reinforced the top portion of each column with a steel skirt. Sharma et al. (2004) used horizontal layers of geogrid in the top portion of each column. Rao and Bhandari (1980) used concrete plugs or cement grout to prevent lateral bulging of the columns. Juran and Riccobono (1991) suggested mixing the granular material that is placed at the top of each column with cement.

Another method that can be used to provide the required lateral confining pressure to increase the bearing capacity of granular columns is to encase the column with a suitable geosynthetic, to form a geosynthetic-encased column (GEC). Using a high-strength geosynthetic for confinement not only increases the strength of a granular column, but also prevents lateral displacement of the column material into the very soft surrounding soil. The use of encasement for granular columns was first suggested by Van Impe and Silence (1986) and Van Impe (1989). This technique has been successfully used in different projects (e.g. Kempfert and Raithel 2002; Raithel et al. 2005; de Mello et al. 2008).

In Germany, since 1994, extensive studies have been performed to develop a better understanding of the behaviour and performance of GECs (Alexiew et al. 2005). Raithel and Kempfert (2000) developed an analytical procedure based on the assumption of unit cell behaviour and equal settlement for the column and soft surrounding soil. Paul and Ponomarjow (2004) provided some suggestions for the design of geogrid-reinforced crushed stone columns. Alexiew et al. (2005) described a series of design principles, technologies and procedures for GECs and emphasised the importance of the tensile modulus of the geotextile that is used for column confinement. Lee et al. (2008) investigated the improvement in load-carrying capacity and reduction in bulging that occurs in a geogridencased stone column using field load tests. Wu et al. (2009) developed an analytical procedure that assumes a normalised relationship between the volumetric change and the axial strain of the column material. They then used this technique to investigate the stress-strain behaviour of a GEC that was subjected to monotonically increasing lateral pressures.
Improved performance of GECs over conventional granular columns has been verified by extensive laboratory tests. Al-Joulani and Bauer (1995) observed an increase in the load capacity of GECs that was both strain-dependent and a function of the dilatancy of the column material. The increase in the shear strength of the GECs was expressed as a cohesion intercept on the Mohr-Coulomb strength envelope. Sivakumar et al. (2004) and Malarvizhi and Ilamparuthi (2004) carried out laboratory model tests on end bearing and floating reinforced and unreinforced stone columns. Trunk et al. (2004) performed experimental tests on geogrid wrapped vibro stone columns under static and dynamic loads, without lateral support. Ayadat and Hanna (2005) presented the results of an experimental investigation on the performance of stone columns encapsulated in geofabric installed in a collapsible soil layer and subjected to inundation. Di Prisco et al. (2006) applied a vertical nonmonotonic loading path on small-scale reinforced sand columns and observed improvements in both the stiffness and bearing capacity of the columns. Lee et al. (2007) investigated the failure mechanism and load-carrying capacity of GECs by model tests. Murugesan and Rajagopal (2007) experimentally investigated the effects of column diameter, geosynthetic stiffness and length of encasement on the load-carrying capacity of GECs. They concluded that the performance of partially encased columns is very close to that of fully encased columns. Gniel and Bouazza (2009) compared isolated column behaviour with group column behaviour. Wu and Hong (2009) performed a series of triaxial compression tests on reinforced and unreinforced sand columns. They concluded that using stronger geotextile did not change the friction angle of reinforced specimens; however, it increased the mobilised pseudo-cohesive values.

A number of numerical analyses have also been carried out to study the behaviour of encased columns. Murugesan and Rajagopal (2006) performed axisymmetric numerical analyses and assumed continuum elements for the geosynthetic. To address the interface shear behaviour, they used lower shear strengths for the elements that were adjacent to the geosynthetic encasement. Malarvizhi and Ilamparuthi (2007) also performed axisymmetric numerical analyses and used geogrid elements that only require the specification of axial stiffness to model the encasement. Park et al. (2007) carried out three-dimensional (3-D) numerical analyses for evaluation of GECs. They selected shell elements to model the geogrid. Yoo and Kim (2009) compared the results of axisymmetric, 3-D unit cell and fully 3-D models. Membrane elements were used to model the behaviour of the encasement. They concluded that the results of 3-D unit cells were in good agreement with those from the fully 3-D model. They also noted that axisymmetric modelling tended to give 10-20\% larger results than the 3 -D models, particularly for the vertical effective stress and lateral deformation of the granular column, as well as the strain in the geosynthetic. From the information that is available in the literature, it appears that other researchers have typically not used interface elements to model the behaviour of GECs; the use of 
interface elements is beneficial for simulating the relative displacement that occurs at the interface between the geosynthetic and the surrounding soils.

This paper describes the results of 3-D finite element analyses that were carried out to simulate the behaviour of a single GEC in soft clay using the computer program ABAQUS (Hibbitt, Karlsson and Sorensen Inc. 2007). To compare the performance of the GEC with a granular column, parallel analyses were also performed on a granular column without encasement. The influence of the geosynthetic stiffness, the friction and dilation angle of the column material, the length of geosynthetic encasement, the diameter of the column, the length of column and the coefficient of lateral earth pressure were studied in the numerical analyses.

\section{NUMERICAL ANALYSES}

Finite element analyses were performed using the program ABAQUS (Hibbitt, Karlsson and Sorensen Inc. 2007). As the zone of interest has two planes of symmetry, it was only necessary to numerically model the behaviour of the system over a quarter of the domain. Figure 1 shows a typical finite element mesh used in the analyses. In all of the numerical analyses that were performed, the thickness of the soft soil and the length of the column were assumed to be $5 \mathrm{~m}$. It was also assumed that the soil and column were underlain by a rigid layer. The lateral extent of the soft soil around the column (the radius of the modelled zone of interest) was selected such that the numerical model results were not affected by the imposed conditions along the circumferential boundary of the soft soil. As shown in Figure 1, when the radius of the granular column was $0.4 \mathrm{~m}$ the overall radius of the cylinder was selected to be $2.0 \mathrm{~m}$. At the bottom boundary of the finite element mesh, the displacements were set to zero in the $z$ direction. The displacements in the $x$ and $y$ directions were set to zero on the circumferential boundary of the soft soil zone. On the planes of symmetry, normal displacement was set to zero.

The finite element mesh used in the numerical simulations was developed using six-node linear triangular prism elements for both the granular column and soft soil. The granular column was modelled using a linear elasticperfectly plastic model with Mohr-Coulomb failure criterion. The Mohr-Coulomb model is defined by five parameters: effective friction angle $(\phi)$, effective cohesion $(c)$, dilation angle $(\psi)$, elastic modulus $(E)$ and Poisson's ratio $(v)$. The parameters used in the numerical analyses are summarised in Table 1. The Mohr-Coulomb para-

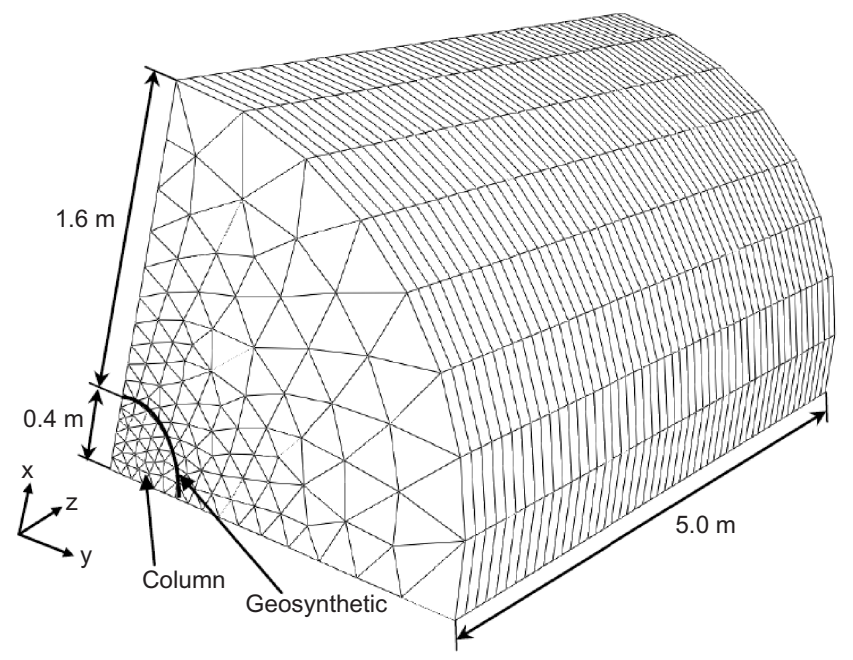

Figure 1. Typical finite element mesh used in the analyses

meters used in the numerical analyses are similar to the typical values used by other researchers (e.g. Guetif et al. 2007; Ambily and Gandhi 2007).

The soft soil was modelled as a modified Cam Clay material. Five material parameters are associated with this model, namely the slope of the swelling line $(\kappa)$, the slope of the virgin consolidation line $(\lambda)$, the void ratio at unit pressure (e), the slope of the critical state line $(M)$ and Poisson's ratio $(v)$. The modified Cam Clay parameters used corresponded to those obtained for experimental data on soft Bangkok clay (Balasubramanian and Chaudhry 1978). These parameters are listed in Table 1.

The geosynthetic was modelled using four-node quadrilateral, reduced integration membrane elements. The geosynthetic was assumed to be an orthotropic linear elastic material, with an assumed Poisson's ratio of 0.3 (e.g. Murugesan and Rajagopal 2006; Liu et al. 2007). Alexiew et al. (2005) documented that design values of tensile modulus $(J)$ between 2000 and $4000 \mathrm{kN} / \mathrm{m}$ were required for the geosynthetic used to encase granular columns on a number of different projects (the tensile modulus of the encasement, $J$, is also commonly referred to as the geosynthetic stiffness, e.g. Murugesan and Rajagopal 2006; Smith and Filz 2007). Consequently, a value of $J=3000 \mathrm{kN} / \mathrm{m}$ was used in the numerical analyses. A circumferential elastic modulus $\left(E_{\mathrm{c}}\right)$ of $600 \mathrm{MPa}$ was used for the geosynthetic, which was derived from the relationship $E_{\mathrm{c}}=J / t$ (e.g. Murugesan and Rajagopal 2006; Smith and Filz 2007). The thickness of the geosynthetic $(t)$ was assumed to be $5 \mathrm{~mm}$ for all of the numerical analyses that were performed; this value is in accordance with the range of 3 to $7 \mathrm{~mm}$ thickness that is

Table 1. Model parameters

\begin{tabular}{|c|c|c|c|c|c|c|c|c|c|c|c|}
\hline Part & Model & $\begin{array}{l}\phi \\
\left({ }^{\circ}\right)\end{array}$ & $\begin{array}{c}c \\
(\mathrm{kPa})\end{array}$ & $\begin{array}{l}\psi \\
\left({ }^{\circ}\right)\end{array}$ & $\begin{array}{c}E \\
(\mathrm{MPa})\end{array}$ & $\begin{array}{c}E_{\mathrm{c}} \\
(\mathrm{MPa})\end{array}$ & $v$ & $\kappa$ & $\lambda$ & $M$ & $e$ \\
\hline $\begin{array}{l}\text { Stone column } \\
\text { Soft soil } \\
\text { Geosynthetic }\end{array}$ & $\begin{array}{l}\text { Mohr-Coulomb } \\
\text { Modified Cam Clay } \\
\text { Linear elastic }\end{array}$ & 40 & 1 & 0 & 60 & 600 & $\begin{array}{l}0.30 \\
0.20 \\
0.30\end{array}$ & 0.09 & 0.51 & 1.00 & 2.00 \\
\hline
\end{tabular}


typically used for modelling this material (e.g. Sharma et al. 2004; Park et al. 2007).

The assumption of orthotropic material behaviour for the geosynthetic is based upon a prior comprehensive study of numerical results (Khabbazian et al. 2009), which indicated that using an isotropic linear elastic material for encasement can increase the bearing capacity of a column up to $10 \%$ and adversely affect the shape of lateral bulging. In order not to adversely influence the numerical results, and knowing that the encasement did not carry vertical (compressive) load, the longitudinal elastic modulus $\left(E_{1}\right)$ of the encasement was decreased to $1 \%$ of the circumferential elastic modulus (i.e., $E_{1}=0.01 E_{\mathrm{c}}$ ). Further decreases in the longitudinal elastic modulus beyond this value had no effect on the numerical results.

Interface elements that can be characterised by two sets of parameters were used to model interaction behaviour between the geosynthetic and the granular column, and between the geosynthetic and the surrounding soft soil. A Mohr-Coulomb failure criterion with zero cohesion was used for the interface elements. The coefficient of sliding friction $(\mu)$ between the geosynthetic and the granular column was selected to be $0.5(\mu=2 / 3 \tan \phi)$ (Elias et al. 2006), where $\phi$ is the friction angle of the column material. For interaction between the geosynthetic and the soft soil, $\mu$ was assumed to be $0.3 \quad(\mu=0.7 \tan \phi)$ (Abu-Farsakhl et al. 2007), where $\phi$ is the friction angle of the soft soil.

In order to compare the performance of the GEC with a conventional granular column, parallel analyses were also performed on a granular column without encasement. In this case, in order to have similar interaction in the granular column simulations to that observed between the geosynthetic and the surrounding soft soil in the GEC simulations, the coefficient of sliding friction between the granular column and the soft soil was selected to be 0.3 (the same number as that used for the geosynthetic/soft soil interaction in the GEC simulations, following the guidance provided by Abu-Farsakhl et al. (2007)).

\section{NUMERICAL RESULTS}

In order to determine the stress-settlement behaviour on top of the GEC, soil nodal points corresponding to the top of the column were subjected to a series of vertical downward displacements. The surrounding soil nodes were not displaced directly as part of this process (they were left to displace freely), as the goal of these analyses was to examine the behaviour of a single column that is being used to support an applied structural load (such as what might be applied by a building foundation). More complex group loading behaviour, such as that observed in pile-supported embankments where settlement and stress arching occurs between columns (e.g. Smith and Filz 2007; Huang and Han 2009; Yoo and Kim 2009), is beyond the scope of this work. As vertical displacements were applied to the top of the column, the resultant stress was recorded, allowing the stress-settlement curve to be drawn accordingly.

Figure 2 shows the stress-settlement response for both a GEC and a granular column having the parameters listed

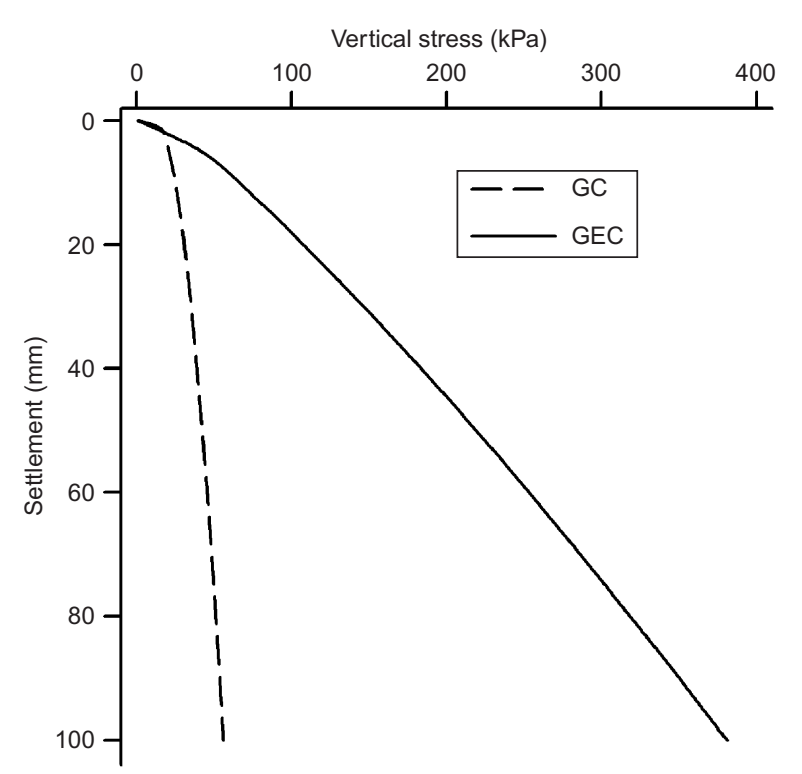

Figure 2. Settlement vs. stress for a granular column and a GEC

in Table 1. From Figure 2, it can be seen that after a very small vertical settlement, the mobilised vertical stress on top of the encased column was always greater than the granular column and the difference increased with additional settlement. For example, at a settlement of $25 \mathrm{~mm}$ (a common serviceability criteria), the mobilised vertical stress on top of the GEC was 3.8 times greater than that of the granular column. This ratio became 5.4 and 6.8 for settlements of 50 and $100 \mathrm{~mm}$, respectively.

The lateral bulging of the GEC and granular column at a settlement of $50 \mathrm{~mm}$ is shown in Figure 3. It can be seen that in the granular column, lateral bulging occurred up to a depth of $1.2 \mathrm{~m}$ (1.5D, where $D$ is the column diameter). At greater depths, the lateral bulging became negligible. For the GEC, the maximum value of lateral displacement was much less than that for the granular column. However,

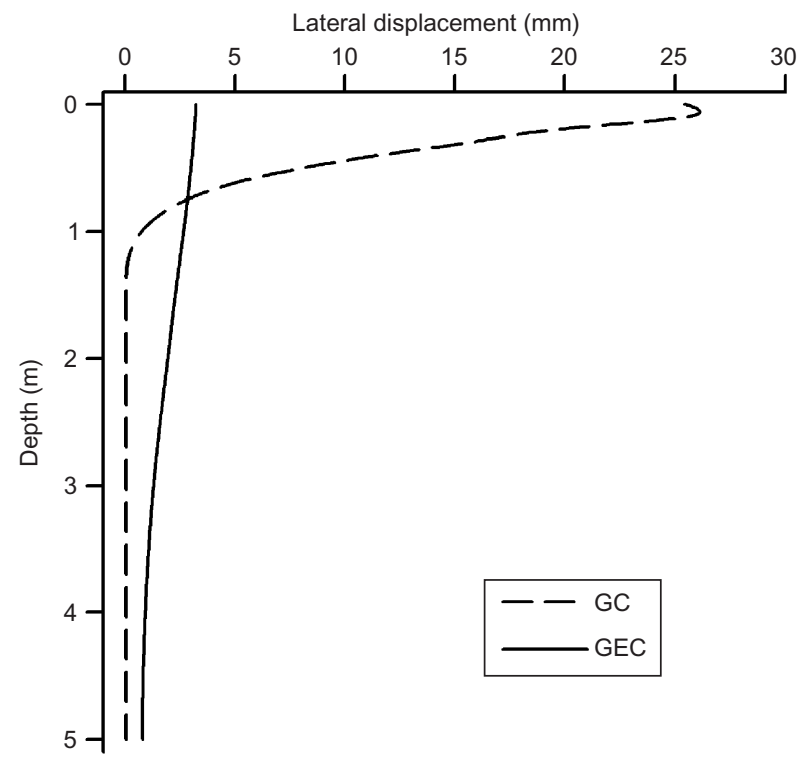

Figure 3. Lateral bulging vs. depth for a granular column and a GEC at a vertical settlement of $50 \mathrm{~mm}$ 
after a depth of $1 D$, the GEC experienced more lateral displacement than the granular column. This was attributed to both the increased stress at the top of the GEC (Figure 2) and deeper transmission of the load due to the effect of the encasement.

Figure 4 shows the resultant hoop tension force along the length of the granular column at settlements of 25 and $50 \mathrm{~mm}$. It is clear that the maximum hoop tension force occurred at the ground surface and decreased with depth. Numerical results also showed that the maximum strain in the geosynthetic was less than $1 \%$, which is consistent with the assumption of linear elastic behaviour for the encasement.

\section{PARAMETRIC STUDY}

In order to investigate the influence of a number of the input parameters on the behaviour of the GEC, a series of parametric analyses were performed. In these analyses, only one parameter was changed and all of the other parameters were held constant at the base values. The 'base' model parameters are those listed in Table 1.

\subsection{Influence of geosynthetic stiffness}

To investigate the influence of the geosynthetic encasement stiffness on the performance of the GEC, the stiffness $(J)$ was varied over a wide range of values from 300 to $10000 \mathrm{kN} / \mathrm{m}$. Figure 5 shows the stress-settlement curves for the top of the column for different values of encasement stiffness. It is evident that the performance of the column improved significantly with an increase in stiffness of the encasement. The mobilised stresses at the top of the GEC at a vertical settlement of 25 and $50 \mathrm{~mm}$ are shown in Figure 6 for different geosynthetic stiffnesses. Figures 5 and 6 show that the stress-settlement response of GECs strongly depended on the value of encasement stiffness. For example, at a settlement of 25 and $50 \mathrm{~mm}$, if the stiffness of the encasement changed from 1000 to $3000 \mathrm{kN} / \mathrm{m}$, the corresponding stress that was mobilised in the column was increased by as much as $90 \%$.

Figure 7 shows the lateral displacement of columns at a vertical stress of $100 \mathrm{kPa}$ with different values of encase-

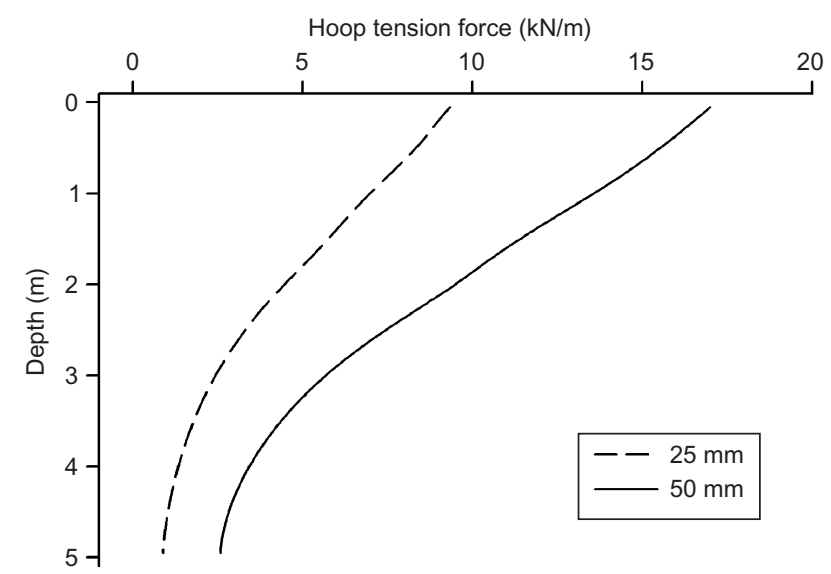

Figure 4. Hoop tension force in the geosynthetic vs. depth

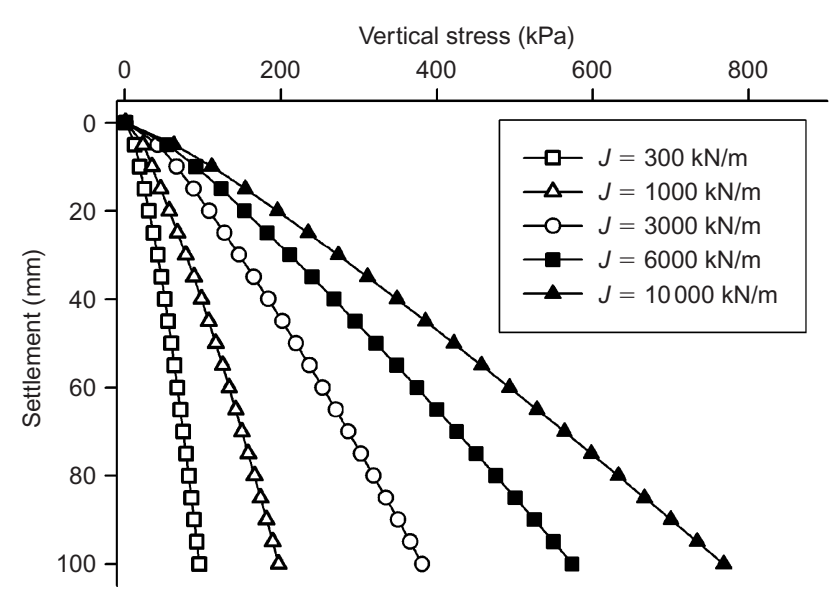

Figure 5. Effect of changes in encasement stiffness on the stress-settlement behaviour of a GEC

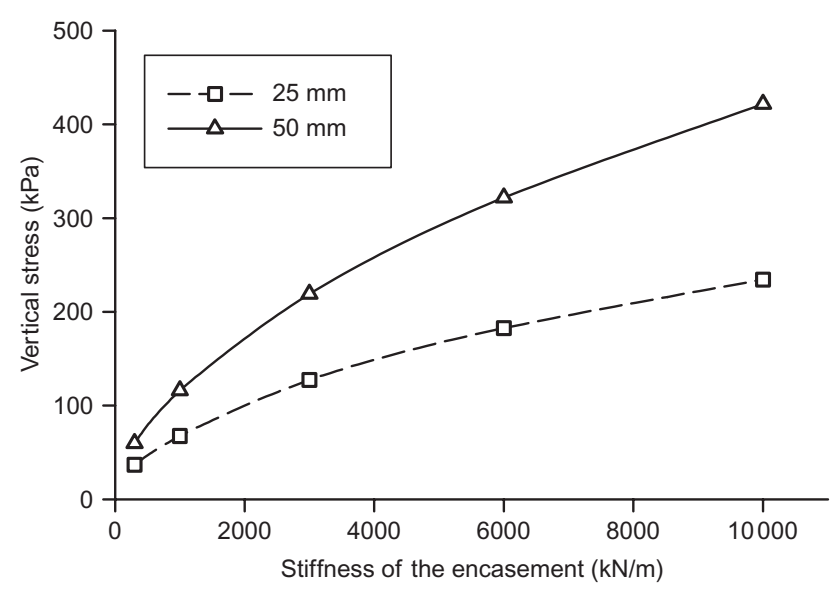

Figure 6. Mobilised vertical stress in a GEC as a function of encasement stiffness

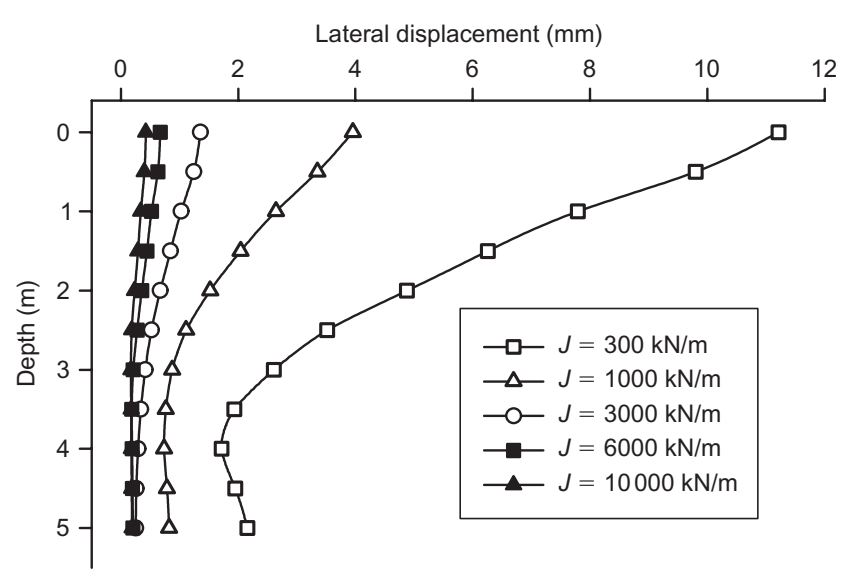

Figure 7. Lateral displacement vs. depth at a vertical stress of $100 \mathrm{kPa}$ for a GEC with varying encasement stiffness

ment stiffness. At the small values of stiffness, increases in the stiffness substantially decreased the lateral bulging; however, for higher stiffnesses, the variation of lateral displacement was insignificant. When results from GEC simulations were compared with those for granular columns, it was observed that the use of even low-stiffness 
encasement significantly improved the performance of the column, as the load in the GEC was distributed over significantly larger depths (e.g. greater than $3 \mathrm{~m}$ at a vertical stress of $100 \mathrm{kPa}$; Figure 7).

\subsection{Effect of friction angle and dilation angle of granular column material}

Three analyses were performed with different values of friction angle $\left(35,40\right.$ and $\left.45^{\circ}\right)$ for the column material that was encased in the GEC. The resultant stresssettlement curves are presented in Figure 8. The performance of the GEC was improved by increasing the friction angle of the material, as expected. This effect was, however, substantially less of an influence than the encasement stiffness. For example, by increasing the friction angle of the column material from 35 to $45^{\circ}$, the mobilised stress on top of the column at $50 \mathrm{~mm}$ settlement increased by about $50 \%$. This difference was significantly less than the relative changes in mobilised stress value that were observed for changes in the encasement stiffness.

As noted in the previous section, the stiffness of the encasement in a GEC is of critical importance for enhancing the stress-settlement response of the column. By extension, the authors hypothesise that accurately capturing the shear-induced volume change that occurs in the encased granular material may also be quite important, as it is the volumetric response of the encased material that mobilises tensile stresses in the encasement, allowing for superior stress-settlement column performance. A highly dilative column material would probably be desirable, as it should more efficiently mobilise the stress in the encasement under application of axial load to the column. This would increase the confining pressure in the column material at smaller axial displacements, leading to less column settlement under the applied load. Consequently, for accurate numerical modelling of GECs, the use of a constitutive model that captures the volumetric strain response during shear may be beneficial.

The Mohr-Coulomb model has limitations for characterising shear-induced volume change in a robust way. Historically, the way this has been addressed by previous researchers who have modelled the behaviour of GECs is through the use of a dilation angle in conjunction with the

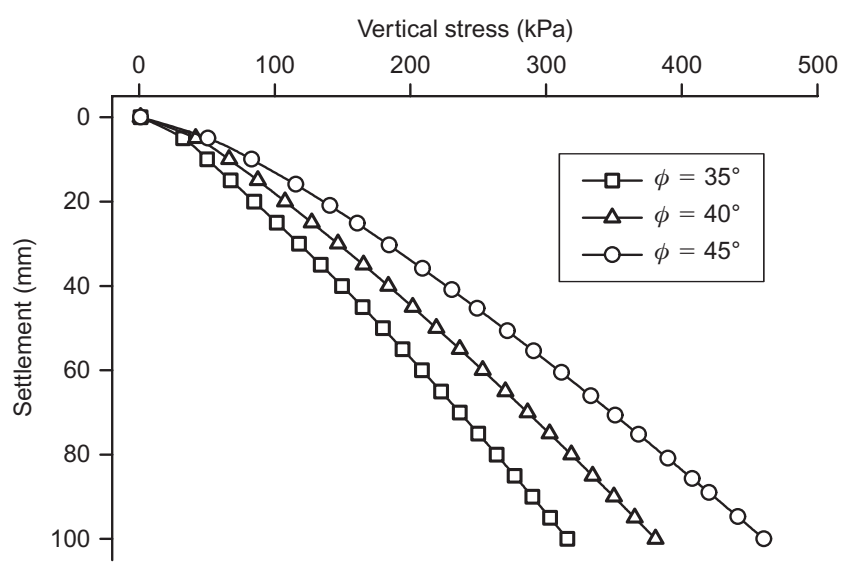

Figure 8. Effect of friction angle on the stress-settlement behaviour of a GEC
Mohr-Coulomb model (e.g. Malarvizhi and Ilamparuthi 2007, Yoo and Kim 2009). For the analyses described here the default value of dilation angle of the column material was assumed to be zero (Table 1). To examine the effect of shear-induced dilation on the stress-settlement response of the column, three analyses with dilation angles of 3,6 and $10^{\circ}$ were also performed. Figure 9 shows the stress-settlement response of columns with different values of dilation angle. The results indicate that an increase of dilation angle from zero to $10^{\circ}$ can enhance the mobilised vertical stress by as much as $20 \%$.

By comparing the relative effects of encasement stiffness and granular column material properties on the stress-settlement response of GECs, it appears that to improve the performance of the GEC it is more efficient to choose encasement with a higher stiffness than to increase the strength parameters of the column materials. It is possible that, if a very stiff and strong granular column is required, improving only the quality of the column materials will not be sufficient to achieve the necessary column capacity.

\subsection{Influence of the length of encasement}

As shown in Figure 3, significant lateral bulging occurs in granular columns up to a depth of 1.5 diameters of the column (1.5D). Hughes and Withers (1974) and Madhav and Miura (1994) have also stated that lateral bulging is the most common failure mode that occurs in the top portion of the granular columns. Consequently, it may be sufficient to partially encase only the top portion of the column, while still achieving essentially the same performance as for a fully encased column. The influence of partial encasement on column performance was studied by varying the length of encasement $\left(L_{\mathrm{enc}}\right)$ from $0.8 \mathrm{~m}(1 D)$ to $4.0 \mathrm{~m}(5 D)$. Stress-settlement results for partially encased columns are presented in Figure 10.

From Figure 10, it is clear that increases in the length of encasement improved the performance of the GEC. As the length of encasement increased, the stress-settlement response of a partially encased column approached that of a fully encased column.

To better understand the behaviour of partially encased columns, mobilised vertical stresses at vertical settlements

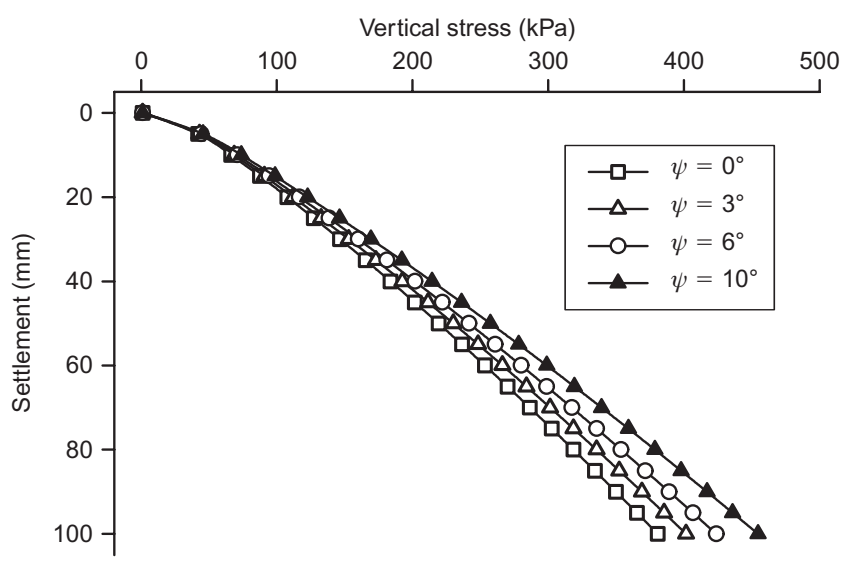

Figure 9. Effect of dilation angle on the stress-settlement behaviour of a GEC 


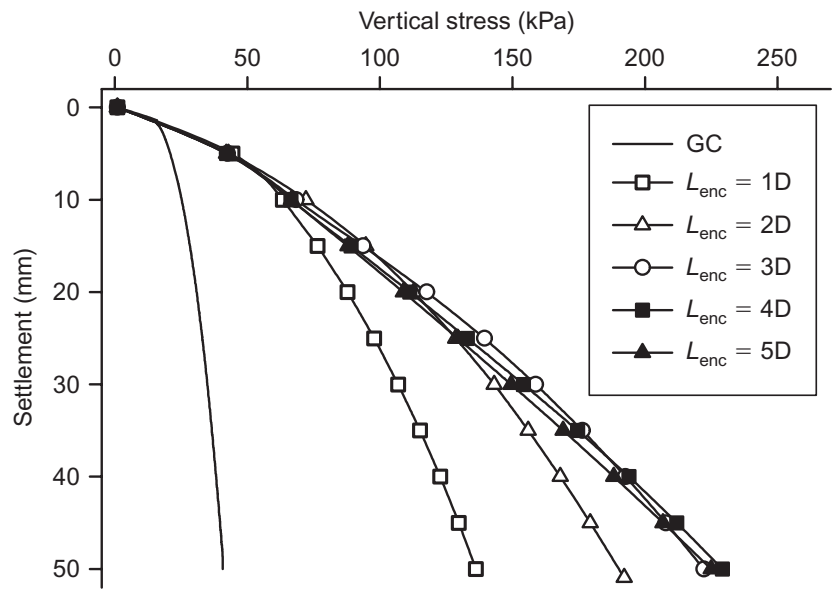

Figure 10. Effect of length of encasement on the stresssettlement behaviour of a partially encased column

of 25,50 and $100 \mathrm{~mm}$ are presented in Figure 11. At a settlement of $25 \mathrm{~mm}$, encasing a granular column was efficient up to a depth of $2 D$, after which further increases in the length of encasement did not change the stresssettlement response of the column. This optimum length of geosynthetic increases to $3 D$ and $4 D$ at settlements of 50 and $100 \mathrm{~mm}$, respectively. Accordingly, the effectiveness of partially encasing columns to achieve the same performance as fully encased columns is related to the level of loads applied at the top of the column. This finding is significant, as other authors have previously tried to find a specific value for the optimum length of geosynthetic. Murugesan and Rajagopal (2006, 2007) performed both numerical analyses and model tests and concluded that the optimum length of encasement was equal to $2 D$ (based on the results of their numerical analyses) and $4 D$ (from their model tests). Yoo and Kim (2009) performed numerical analyses and suggested that different optimum encasement lengths should be selected for short- and long-term loading.

From Figure 10, it can also be seen that encasing a granular column up to a depth of only one diameter can significantly improve its performance. For example, at a settlement of $50 \mathrm{~mm}$, the mobilised vertical stress in a

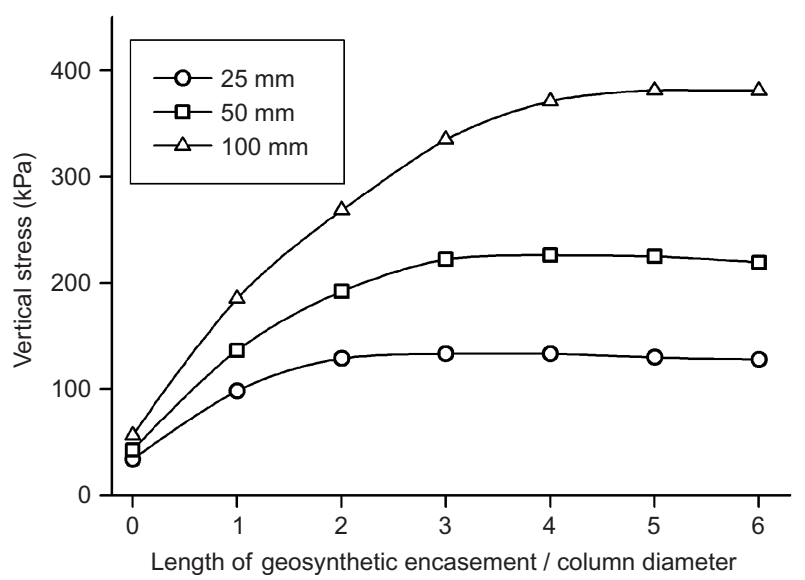

Figure 11. Mobilised vertical stress in a GEC as a function of length of encasement partially encased column with a length of $1 D$ was 4.5 times greater than that for a conventional granular column.

Lateral bulging of partially encased columns having encasement lengths of $1 D, 2 D$ and $3 D$ are presented together with a fully encased column in Figure 12, for a vertical settlement of $50 \mathrm{~mm}$. As the length of encasement increased from $1 D$ to $3 D$, the maximum value of lateral displacement decreased. However, after a length of $3 D$, additional increases in the length of encasement did not change the maximum lateral displacement. By comparing the results shown in Figures 3 and 12, it can be observed that encasement of granular columns even up to a depth of $1 D$ can considerably decrease the maximum lateral displacement. For example, at a settlement of $50 \mathrm{~mm}$, the maximum lateral displacement of a granular column is 3.5 times greater than that of a partially encased column with length of encasement equal to $1 D$.

\subsection{Influence of geosynthetic-encased column diameter}

Murugesan and Rajagopal (2007) studied the load capacity of encased stone columns through laboratory model tests and concluded that the stresses developed in the columns decreased with an increase in the column diameter. For the present study, this behaviour was explored by varying the column diameter $(D)$ from 0.6 to $1.5 \mathrm{~m}(0.6,0.8,1.0$, 1.2 and $1.5 \mathrm{~m})$. For each of the column diameters that were analysed, soil nodal points corresponding to the top of the entire column were subjected to a series of vertical downward displacements, without applying displacement directly to the surrounding soil nodes (they were left to displace freely). For each of the columns, the radial extent of the soft soil around the GEC was varied to minimise the effect of the boundary condition on the column behaviour.

Figure 13 illustrates the mobilised vertical stresses at vertical settlements of 25, 50 and $100 \mathrm{~mm}$ for GECs of varying diameters. Results from these analyses indicate that as the diameter of the GEC increased, the mobilised vertical stress on top of the column decreased. For

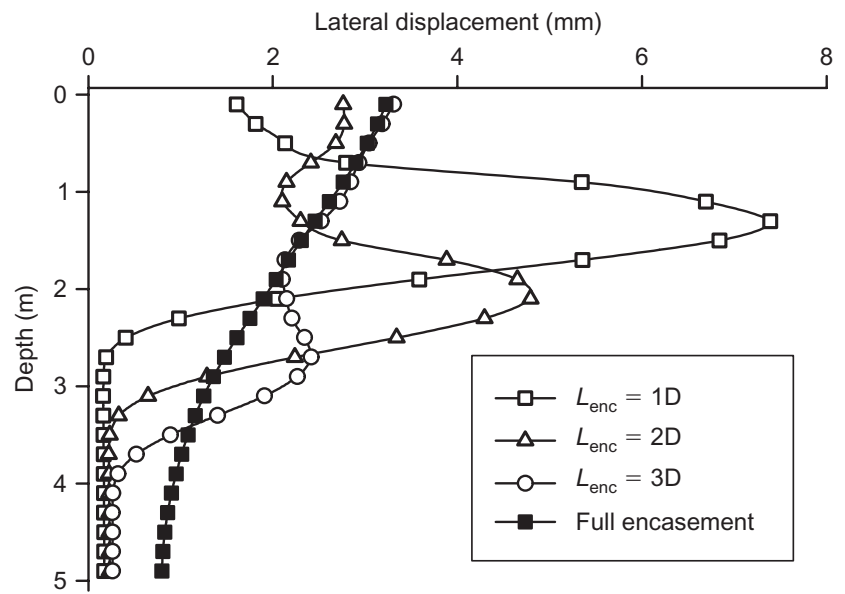

Figure 12. Lateral displacement vs. depth at a settlement of $50 \mathrm{~mm}$ for a GEC with varying length of encasement 


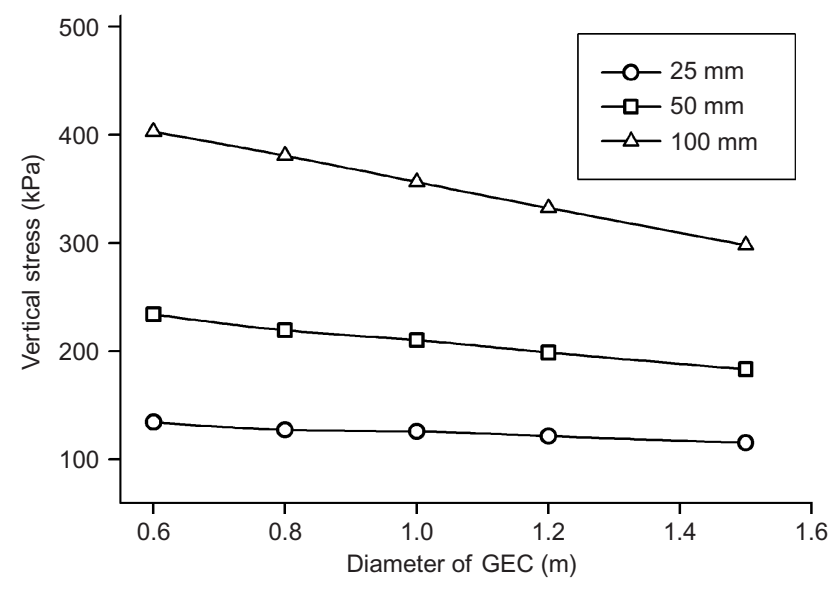

Figure 13. Mobilised vertical stress in a GEC as a function of column diameter

example, by changing the diameter of the GEC from 0.6 to $1.5 \mathrm{~m}$, the mobilised vertical stress at a settlement of $50 \mathrm{~mm}$ decreased by as much as $21 \%$. Figure 13 also shows that the influence of column diameter increased with increasing vertical settlements; this is reasonable, as larger settlements corresponded to larger loads in the column. For example, by changing the diameter of GECs from 0.6 to $1.5 \mathrm{~m}$, the mobilised vertical stresses at settlements of 25 and $100 \mathrm{~mm}$ decreased by as much as 14 and $26 \%$, respectively.

Lateral displacements of varying-diameter GECs at a vertical stress of $100 \mathrm{kPa}$ are presented in Figure 14. As shown, the lateral displacement increased with the diameter of the column. This increase was noticeable up to depths of 2.5 to $3 \mathrm{~m}$, after which point the relative lateral displacement of the columns was not significantly affected by the column diameter.

Based on the results shown in Figures 13 and 14, using smaller diameter GECs is a more efficient use of construction materials than the use of large diameter columns. However, there is a trade-off in additional cost and time required for installation of multiple smaller columns. This trade-off is often partially countered or otherwise offset by difficulties that are commonly encountered when excavat-

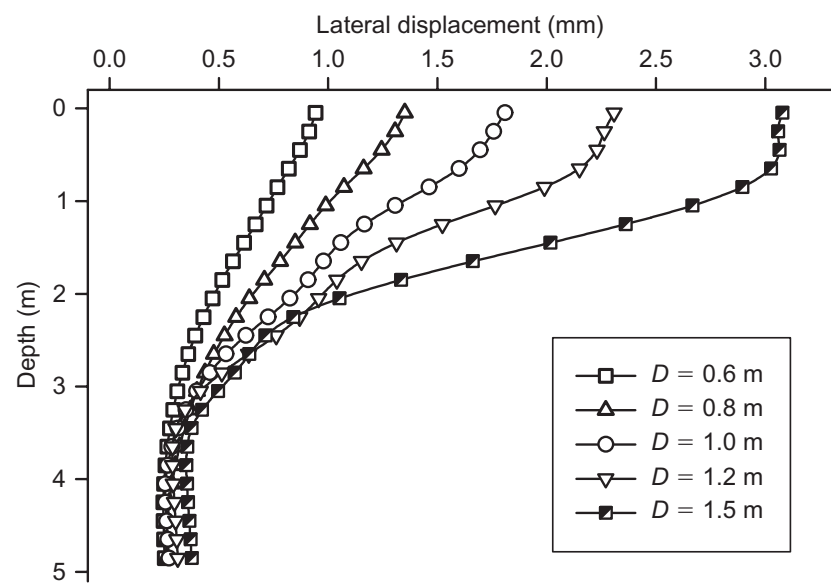

Figure 14. Lateral displacement vs. depth at a vertical stress of $100 \mathrm{kPa}$ for a GEC with varying column diameter ing larger diameter holes. These additional factors need to be accounted for by the design engineer when optimising the design of GECs for a specific project.

\subsection{Influence of granular column length}

In order to examine the influence of the length of the column on the calculated numerical results, three analyses were performed on granular columns with lengths $\left(L_{\mathrm{col}}\right)$ of 2.5, 5.0 and $7.5 \mathrm{~m}$. As noted previously, at the bottom boundary of each of these columns, the displacements were set to zero in the $z$ direction. This means that the columns that were being modelled were end bearing on a rigid base and could not be considered to be 'floating' columns.

The variations of vertical stresses versus settlement for all three analyses are presented in Figure 15. As can be seen in Figure 15, a granular column with a length of $7.5 \mathrm{~m}$ behaved like a $5.0 \mathrm{~m}$ long column. This can be attributed to the failure mechanism of both columns, lateral bulging, which happens within the top portion of the columns (Madhav and Miura 1994). As the length of the granular column changed from 5.0 to $2.5 \mathrm{~m}$, the column exhibited an improved stress-settlement response. This improvement decreased with vertical settlement. As an example, a $2.5 \mathrm{~m}$ granular column is initially stiffer than a $5.0 \mathrm{~m}$ column (in the elastic range of behaviour) and behaves in a very similar manner to a $5 \mathrm{~m}$ (or $7.5 \mathrm{~m}$ ) long column when it begins to settle and experiences lateral bulging (in the plastic range of behaviour). Consequently, except for very short columns, changes in the length of conventional granular columns typically do not affect their stress-settlement behaviour.

To study the effect of column length on the stresssettlement behaviour of GECs, four analyses were carried out on GECs with lengths of 2.5, 5.0, 7.5 and $10.0 \mathrm{~m}$. Numerical analyses showed that the stress-settlement performance of GECs decreased as their length increased (Figure 16). Figure 16 shows that as the column length was increased from 2.5 to $10.0 \mathrm{~m}$, the stress-settlement performance of the column decreased.

Figure 17 illustrates the mobilised vertical stresses at vertical settlements of 25, 50 and $100 \mathrm{~mm}$ for GECs of

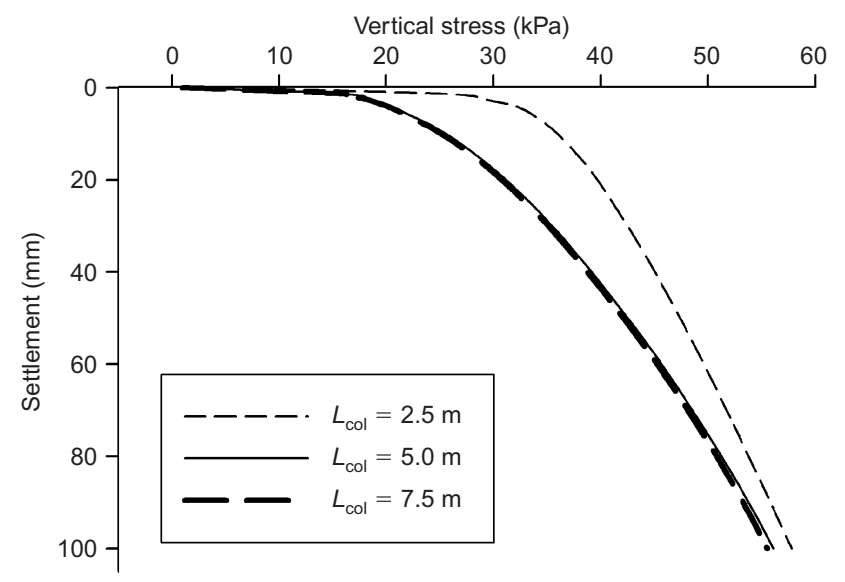

Figure 15. Effect of column length on the stress-settlement behaviour of a granular column 


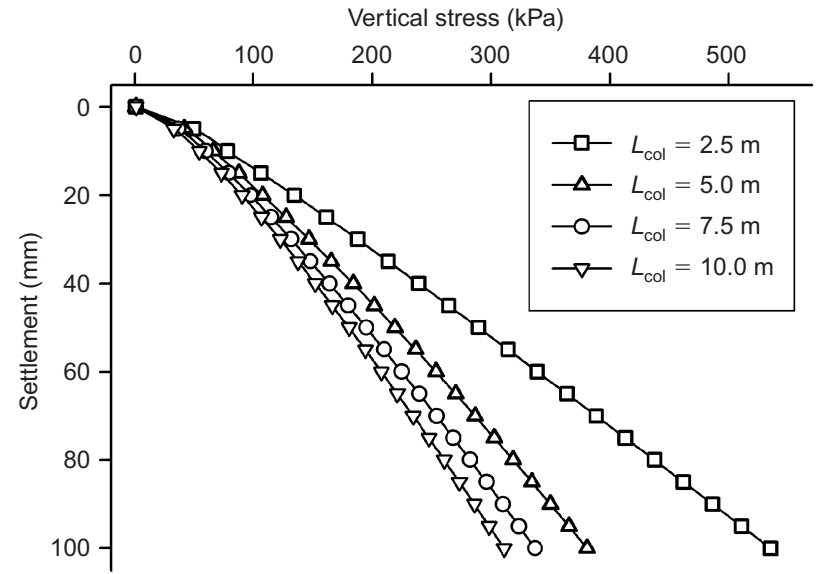

Figure 16. Effect of column length on the stress-settlement behaviour of a GEC

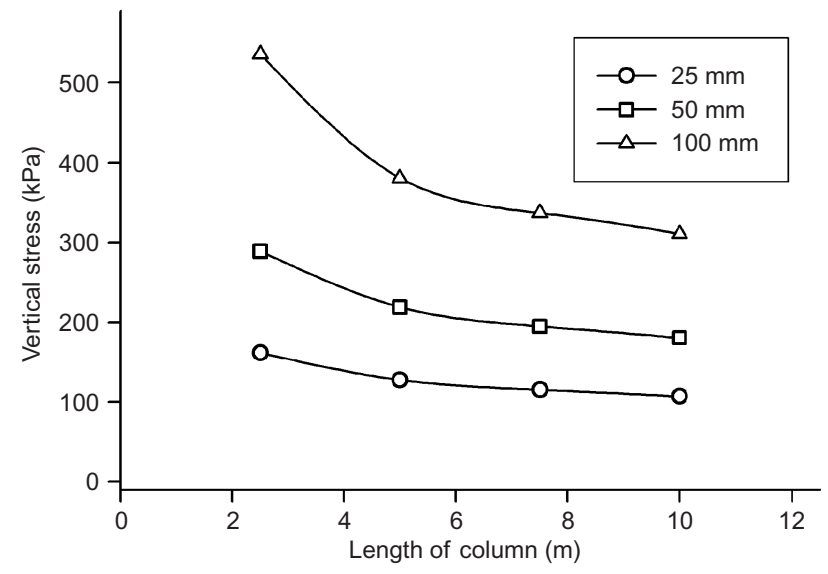

Figure 17. Mobilised vertical stress in a GEC as a function of column length

different lengths. From Figures 16 and 17, it is evident that the influence of column length was more substantial for short columns at higher settlements. For example, at vertical settlements of 25 and $100 \mathrm{~mm}$, the vertical stress on a $2.5 \mathrm{~m}$ column was 26 and $40 \%$ greater than that on a $5.0 \mathrm{~m}$ column, respectively; however, at vertical settlements of 25 and $100 \mathrm{~mm}$, the vertical stress on a $7.5 \mathrm{~m}$ column was only about $8 \%$ greater than that on a $10.0 \mathrm{~m}$ column.

The ratios of load-carrying capacity of GECs to that of granular columns at vertical settlements of 25, 50 and $100 \mathrm{~mm}$ are presented in Figure 18 with respect to the length of columns. It can be seen from Figure 18 that this ratio decreased as the length of column increased and the rate of decrease was more considerable at higher vertical settlements. This implies that the encasing of granular columns to enhance their stress-settlement performance is more efficient for shorter columns than for longer ones. This observation is reasonable, as shorter encased columns exhibit more lateral bulging at the same vertical settlement than do longer encased columns, mobilising confining pressures in the geosynthetic encasement more rapidly. This increased confinement allows shorter encased columns to behave more rigidly under an applied load.

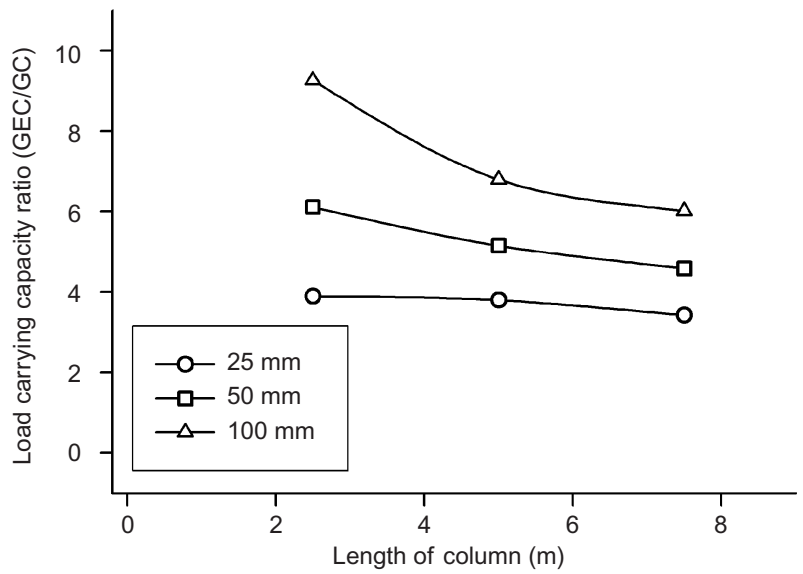

Figure 18. Influence of column length on the relative loadcarrying capacity of a GEC and a granular column

\subsection{Influence of coefficient of lateral earth pressure}

For the initial numerical analyses that were performed, the lateral earth pressure applied to the geosynthetic by the surrounding clay was assumed to correspond to an 'at-rest' earth pressure condition. As such, base values for the lateral earth pressure coefficient $(K)$ were determined using the empirical relationship proposed by Brooker and Ireland (1965): $K_{\mathrm{o}}=0.95-\sin \phi$. This coefficient is used in the numerical model to calculate the horizontal stresses that are applied to the column by the surrounding soil and can consequently have an effect on the mobilised 'skin friction' along the side of the foundation element and the associated stress-settlement response of the column. The coefficient of earth pressure at-rest can be as low as 0.4 for soils formed by sedimentation, or up to 3.0 or more for heavily preloaded deposits (Day 2006). For soft or very soft clays, which are the soil types that GECs are potentially most useful in, variations in the at-rest coefficient of earth pressure typically occur between 0.4 and 1 , as these soils are not overconsolidated. Installation-induced disturbance can sometimes cause changes to the value of $K$; however, for very soft clays, it is unlikely that disturbance-induced changes to $K$ will cause it to shift outside of the aforementioned range. To explore the effect of changes in the lateral earth pressure condition on the stress-settlement behaviour of GECs, three $K$-values ranging from 0.4 to 1.0 were considered herein. As shown in Figure 19, the stress-settlement response of encased columns became more favourable when there was an increase in the coefficient of lateral earth pressure, which is expected. At a settlement of $100 \mathrm{~mm}$, as the coefficient of earth pressure changes from 0.4 to 1.0 , the loadcarrying capacity of a GEC can increase by as much as $25 \%$.

\section{CONCLUSIONS}

Three-dimensional finite element analyses were performed to compare the performance of GECs with conventional granular columns. Parametric analyses were also carried out to study the effect of variations in geosynthetic stiffness, friction and dilation angle of the column material, 


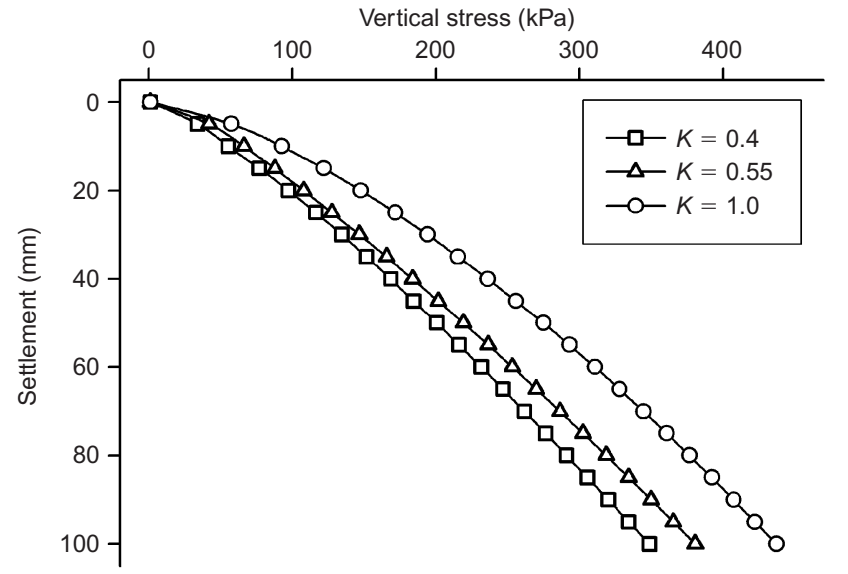

Figure 19. Effect of coefficient of lateral earth pressure on the stress-settlement behaviour of a GEC

length of geosynthetic, column diameter, column length and the coefficient of lateral earth pressure on the behaviour of a GEC. The following conclusions were reached as a result of the numerical analyses performed.

- The stress-settlement response of granular columns can be significantly improved by encasing them. The influence of encasement becomes more noticeable as vertical settlement (or applied pressure) on top of the column increases.

- The maximum value of lateral displacement of a GEC is much less than that of a conventional granular column for the same vertical settlement. This is due to the fact that the increased stiffness of a GEC allows larger loads to be transmitted to greater depths, which in turn causes the lateral displacements to be more evenly distributed over the length of the column than what is observed in a granular column.

- The stiffness of the encasement has a considerable effect on the stress-settlement response of encased granular columns and on their associated loadcarrying capacity.

- Improving the strength characteristics of granular column materials (friction and dilation angle) increases the load-carrying capacity of a given column. However, in many cases, it is more efficient to select encasement with a higher stiffness than it is to improve the column material.

- The optimum length of encasement for achieving the same performance as fully encased granular columns is dependent on the stress applied to the top of the column and the subsequent column settlement. As the settlements (or vertical stresses) on top of the column increase, the required optimum length of encasement increases.

- Decreasing the diameter of an encased granular column improves its stress-settlement response (i.e., larger settlements are observed in larger diameter columns at the same value of applied stress at the top of the column). It was also observed that lateral displacements increase with the diameter of column; this increase in lateral displacement is more noticeable in the top portion of the encased column.

- For granular columns, except for very short columns, increases in the length of column do not significantly affect the stress-settlement behaviour, because failure occurs by lateral bulging in the upper portion of the column. However, for GECs, the stresssettlement response is affected by compression that occurs over the entire length of the column; this means that, at a given displacement, the mobilised stress will be larger in shorter GECs than in longer ones. This is akin to the behaviour of concrete piles under load, where longer piles exhibit larger settlements at the same load than do shorter piles. Consequently, encasing granular columns to improve their stress-settlement behaviour is more efficient for shorter columns than it is for longer ones.

- In situ lateral stresses can influence the stresssettlement response of GECs. Numerical analyses showed that the performance of GECs improves as the coefficient of lateral earth pressure increases.

\section{ACKNOWLEDGEMENTS}

This material is based upon work supported in part by the Geosynthetic Institute under its GSI Fellowship Program.

\section{NOTATIONS}

Basic SI units are given in parentheses.

$c$ effective cohesion $(\mathrm{Pa})$

$D$ diameter of column (m)

$e$ void ratio at unit pressure (dimensionless)

$E$ elastic modulus of encased soil $(\mathrm{Pa})$

$E_{\mathrm{c}}$ circumferential elastic modulus of encasement $(\mathrm{Pa})$

$E_{1}$ longitudinal elastic modulus of encasement $(\mathrm{Pa})$

$J$ tensile modulus $(\mathrm{N} / \mathrm{m})$

$K$ coefficient of lateral earth pressure (dimensionless)

$K_{\mathrm{o}}$ coefficient of lateral earth pressure at rest (dimensionless)

$L_{\text {col }}$ length of column (m)

$L_{\mathrm{enc}}$ length of encasement for a partially encased column (m)

$M$ slope of the critical state line (dimensionless)

$t$ thickness of geosynthetic (m)

$\phi$ effective friction angle $\left(^{\circ}\right)$

$\kappa$ the slope of the swelling line (dimensionless)

$\lambda$ the slope of the virgin consolidation line (dimensionless)

$\mu$ coefficient of sliding friction (dimensionless)

$v$ Poisson's ratio (dimensionless)

$\psi$ dilation angle $\left(^{\circ}\right)$

\section{REFERENCES}

Aboshi, H., Ichimoto, E., Enoki, M. \& Harada, K. (1979). The composera method to improve characteristics of soft clay by inclusion of 
large diameter sand columns. In Proceedings of the International Conference on Soil Reinforcement: Reinforced Earth and other Techniques, Paris, vol. 1, pp. 211-216.

Abu-Farsakhl, M., Coronel, J. \& Tao, M. (2007). Effect of soil moisture content and dry density on cohesive soil-geosynthetic interactions using large direct shear tests. Journal of Materials in Civil Engineering, 19, No. 7, 540-549.

Alexiew, D., Brokemper, D. \& Lothspeich, S. (2005). Geotextile Encased Columns (GEC): load capacity, geotextile selection and pre-design graphs. In Contemporary Issues in Foundation Engineering, Anderson, J. B., Phoon, K. K., Smith, E. \& Loehr, J. E., pp. 1-14. ASCE, Reston, VA, USA, Geotechnical Special Publication 131.

Al-Joulani, N. \& Bauer, G. E. (1995). Laboratory behavior of sleevereinforced stone columns. In Geosynthetics '95 Conference Proceedings, Nashville, TN, pp. 1111-1123.

Ambily, A. P. \& Gandhi, S. R. (2007). Behavior of stone columns based on experimental and FEM analysis. Journal of Geotechnical and Geoenvironmental Engineering, ASCE 133, No. 4, 405-415.

Araujo, G. L. S., Palmeira, E. M. \& Cunha, R. P. (2009). Behaviour of geosynthetic-encased granular columns in porous collapsible soil. Geosynthetics International 16, No. 6, 433-451.

Ayadat, T. \& Hanna, A. M. (2005). Encapsulated stone columns as a soil improvement technique for collapsible soil. Ground Improvement $\mathbf{9}$, No. 4, 137-147.

Balasubramanian, A. S. \& Chaudhry, A. R. (1978). Deformation and strength characteristics of soft Bangkok clay. Journal of the Geotechnical Engineering Division, ASCE 104, No. 9, 1153-1167.

Barksdale, R. D. \& Bachus, R. C. (1983). Design and Construction of Stone Columns Vol. I. Report No. SCEGIT-83-10, Federal Highway Administration, School of Civil Engineering, Georgia Institute of Technology, Atlanta, GA, USA.

Bergado, D. T., Anderson, L. R., Miura, N. \& Balasubramanian, A. S. (1996). Soft Ground Improvement in Lowland and other Environments. ASCE Press, New York, NY, USA.

Brauns, J. (1978). Initial bearing capacity of stone columns and sand piles. In Symposium on Soil Reinforcing and Stabilizing Techniques, Sydney, Australia, pp. 477-496.

Brooker, E. W. \& Ireland, H. O. (1965). Earth pressures at rest related to stress history. Canadian Geotechnical Journal 2, No. 1, 1-15.

Day, R. W. (2006). Foundation Engineering Handbook: Design and Construction with the 2006 International Building Code. McGrawHill, New York, NY, USA.

de Mello, L. G., Mondolfo, M., Montez, F., Tsukahara, C. N. \& Bilfinger, W. (2008). First use of geosynthetic encased sand columns in South America. In Proceedings of 1 st Pan-American Geosynthetics Conference, Cancun, Mexico, pp. 1332-1341.

Di Prisco, C., Galli, A., Cantarelli, E. \& Bongiorno, D. (2006). Georeinforced sand columns: small scale experimental tests and theoretical modeling. In Proceedings of the 8th International Conference on Geosynthetics, Yokohama, Japan, pp. 1685-1688.

Elias, V., Welsh, J., Warren, J., Lukas, R., Collin, G. \& Berg, R. R. (2006). Ground Improvement Methods, Vol. II. Federal Highway Administration, Washington, DC, USA, FHWA-NHI-06-020.

Gniel, J. \& Bouazza, A. (2009). Improvement of soft soils using geogrid encased stone columns. Geotextiles and Geomembranes 27, No. 3, $167-175$.

Greenwood, D. A. (1970). Mechanical improvement of soils below surface. In Proceedings of Conference on Ground Engineering, pp. 11-22. Institution of Civil Engineers, London, UK.

Guetif, Z., Bouassida, M. \& Debats, J. M. (2007). Improved soft clay characteristics due to stone column installation. Computers and Geotechnics 34, No. 2, 104-111.

Hibbitt, Karlsson and Sorensen Inc. (2007). ABAQUS User's Manual, Version 6.7. Hibbitt, Karlsson and Sorensen Inc. Pawtucket, RI, USA.

Huang, J. \& Han, J. (2009). 3D coupled mechanical and hydraulic modeling of a geosynthetic-reinforced deep mixed columnsupported embankment. Geotextiles and Geomembranes 27, No. 4, $272-280$.

Hughes, J. M. O. \& Withers, N. J. (1974). Reinforcing of soft cohesive soils with stone columns. Ground Engineering 7, No. 3, 42-49.
Hughes, J. M. O., Withers, N. J. \& Greenwood, D. A. (1975). A field trial of the reinforcing effect of a stone column in soil. Geotechnique $\mathbf{2 5}$, No. $1,31-44$.

Juran, I. \& Riccobono, O. (1991). Reinforced soft soils with artificially cemented compacted-sand columns. Journal of Geotechnical Engineering, ASCE 117, No. 7, 1042-1060.

Juran, I., Ider, H. M., Acar, Y. B. \& Guermazi, A. (1988). A Comparative Study of Soil Improvement/Reinforcement Technique for Highway Embankments. Research Report, Louisiana Transportation Center, Louisiana State University, Department of Civil Engineering, Baton Rouge, LA, USA.

Kempfert, H.-G. \& Raithel, M. (2002). Experiences on dike foundations and land fills on very soft soils. Technical Committee TC 36 Soft Soils Foundation Engineering. In International Symposium on Soft Soils Foundation Engineering in Mexico 2002.

Khabbazian, M., Kaliakin, V. N. \& Meehan, C. L. (2009). 3D analyses of geosynthetic encased stone columns. In Proceedings of International Foundations Congress and Equipment Expo 09 (IFCEE09), Contemporary Topics in Ground Modification, Problem Soils, and Geo-Support, Geotechnical Special Publication No. 187, Orlando, FL, March 15-19, pp. 201-208. ASCE, New York, USA.

Lee, D., Yoo, C. \& Park, S. (2007). Model tests for analysis of load carrying capacity of geogrid encased stone column. In Proceeding of the Seventeenth International Offshore and Polar Engineering Conference, Lisbon, Portugal, July 1-6, pp. 1632-1635.

Lee, D., Yoo, C., Park, S. \& Jung, S. (2008). Field load tests of geogrid encased stone columns in soft ground. In Proceedings of Eighteenth International Offshore and Polar Engineering Conference, Vancouver, BC, Canada, July $6-11$, pp. 521-524.

Liu, H. L., Ng, C. W. W. \& Fei, K. (2007). Performance of a geogridreinforced and pile-supported highway embankment over soft clay: case study. Journal of Geotechnical and Geoenvironmental Engineering 133, No. 12, 1483-1493.

Madhav, M. R. \& Miura, N. (1994). Soil improvement panel report on stone columns. In Proceedings of the 13th International Conference on Soil Mechanics and Foundation Engineering, New Delhi, India, Vol. 5, pp. 163-164.

Madhav, M. R. \& Vitkar, P. P. (1978). Strip footing on weak clay stabilized with granular trench. Canadian Geotechnical Journal 15, No. 4, 605-609.

Malarvizhi, S. N. \& Ilamparuthi, K. (2004). Load versus settlement of clay bed stabilized with stone and reinforced stone columns. In Proceedings of GeoAsia-2004, Seoul, Korea, pp. 322-329.

Malarvizhi, S. N. \& Ilamparuthi, K. (2007). Performance of stone column encased with geogrids. In Proceedings of the 4th International Conference on Soft Soil Engineering, Vancouver, Canada, pp. 309314.

Muir-Wood, D., Hu, D. \& Nash, D. F. T. (2000). Group effects in stone column foundation: model tests. Geotechnique 50, No. 6, 689-698.

Murugesan, S. \& Rajagopal, K. (2006). Geosynthetic-encased stone columns: Numerical evaluation. Geotextiles and Geomembranes 24, No. 6, 349-358.

Murugesan, S. \& Rajagopal, K. (2007). Model tests on geosyntheticencased stone columns. Geosynthetics International 14, No. 6, $346-354$.

Park, S., Yoo, C. \& Lee, D. (2007). A study on the geogrid reinforced stone column system for settlement reduction effect. In Proceedings of the Seventeenth International Offshore and Polar Engineering Conference, Lisbon, Portugal, July 1-6, pp. 1636-1641.

Paul, A. \& Ponomarjow, A. (2004). The bearing behavior of geogrid reinforced crushed stone columns in comparison to non-reinforced concrete pile foundations. In EuroGeo3: Geotechnical Engineering with Geosynthetics, Munich, Germany, pp. 285-288.

Priebe, H. J. (1995). The design of vibro replacement. Ground Engineering 28, No. 10, 31-37.

Raithel, M. \& Kempfert, H. G. (2000). Calculation models for dam foundations with geotextile-coated sand columns. In Proceedings of International Conference on Geotechnical and Geological Engineering, GeoEng 2000, Melbourne, Australia.

Raithel, M., Kirchner, A., Schade, C. \& Leusink, E. (2005). Foundation of construction on very soft soils with geotextile encased columns 
- state of the art. In Contemporary Issues in Foundation Engineering, Anderson, J. B., Phoon, K. K., Smith, E. \& Loehr, J. E. ASCE, Reston, VA, USA, Geotechnical Special Publication 131.

Raju, V. R. (1997). The behaviour of very soft soils improved by vibro replacement. In Proceedings of Ground Improvement Conference, London, pp. 253-259.

Rao, B. G. \& Bhandari, R. K. (1980). Skirting- a new concept in design of heavy storage tank foundation. In Proceedings of the 6th SouthEast Conference on soil Engineering, Taipei, Taiwan, pp. 283-300.

Sharma, R. S., Kumar, B. R. P. \& Nagendra, G. (2004). Compressive load response of granular piles reinforced with geogrids. Canadian Geotechnical Journal 41. No. 1, 187-192.

Sivakumar, V., McKelvey, D., Graham, J. \& Hughes, D. (2004). Triaxial tests on model sand columns in clay. Canadian Geotechnical Journal 41, No. 2, 299-312.

Smith, M. \& Filz, G. (2007). Axisymmetric numerical modeling of a unit cell in geosynthetic-reinforced, column-supported embankments. Geosynthetics International 14, No. 1, 13-22.
Trunk, G., Heerten, A., Poul, A. \& Reuter, E. (2004). Geogrid wrapped vibro stone columns. In EuroGeo3: Geotechnical Engineering with Geosynthetics, Munich, Germany, pp. 289-294.

Van Impe, W. F. (1989). Soil Improvement Techniques and their Evolution, pp. 63-66. Balkema, Rotterdam, The Netherlands.

Van Impe, W. F. \& Silence, P. (1986). Improving of the bearing capacity of weak hydraulic fills by means of geotextiles. In Proceedings of the 3rd International Conference on Geotextiles, Vienna, Austria, pp. 1411-1416.

Wu, C. S. \& Hong, Y. S. (2009). Laboratory tests on geosyntheticencapsulated sand columns. Geotextiles and Geomembrane, 27, No. 2, 107-120.

Wu, C.-S., Hong, Y.-S. \& Lin, H.-C. (2009). Axial stress-strain relation of encapsulated granular column. Computers and Geotechnics 36, No. $1-2,226-240$.

Yoo, C. \& Kim, S. B. (2009). Numerical modeling of geosyntheticencased stone column-reinforced ground. Geosynthetic International 16, No. 3, 116-126.

The Editor welcomes discussion on all papers published in Geosynthetics International. Please email your contribution to discussion@geosynthetics-international.com by 15 December 2010. 